\title{
Efficacy of Vitamin and Antioxidant Supplements in Prevention of Esophageal Cancer: Meta-analysis of Randomized Controlled Trials
}

ORIGINAL ARTICLE

\author{
Seung-Kwon Myung ${ }^{1,2,3}$, Hyo Jin Yang ${ }^{1,3}$ \\ ${ }^{1}$ Department of Family Medicine, Hospital, National Cancer Center, ${ }^{2}$ Cancer Information \& Education Branch, National Cancer \\ Control Institute, National Cancer Center, ${ }^{3}$ Center for Cancer Prevention and Detection, Hospital, National Cancer Center, Goyang, \\ Korea
}

\begin{abstract}
Background: Observational epidemiological studies have shown that higher intakes of vitamins or antioxidants were inversely associated with the risk of esophageal cancer. However, randomized controlled trials (RCTs) have reported no preventive efficacy of vitamin or antioxidant supplements on esophageal cancer. This meta-analysis aimed to investigate the efficacy of vitamin and antioxidant supplements in the prevention of esophageal cancer as reported by RCTs.

Methods: We searched PubMed, EMBASE, and the Cochrane Library in May 2013. Two authors independently reviewed and selected eligible articles based on predetermined selection criteria.

Results: Of 171 articles searched from three databases and relevant bibliographies, 10 RCTs were included in the final analyses. In a fixed-effect meta-analysis of 10 trials, there was no efficacy of vitamin and antioxidant supplements in the prevention of esophageal cancer (relative risk [RR], 1.04; 95\% confidence interval [CI], 0.86-1.25; $1^{2}=0.0 \%$ ). Also, subgroup meta-analyses showed that vitamin and antioxidant supplements had no preventive efficacy on esophageal cancer both in the high risk (RR, $1.04 ; 95 \% \mathrm{Cl}, 0.85-1.28 ; n=4)$ and non-high risk (RR, $1.01 ; 95 \% \mathrm{Cl}, 0.65-1.56 ; n=6)$ groups for esophageal cancer. Further, subgroup meta-analyses revealed no preventive efficacy on esophageal cancer by type of methodological quality and type of vitamin and antioxidant supplements.

Conclusions: Unlike observational epidemiological studies, this meta-analysis of RCTs suggests that there is no clinical evidence to support the efficacy of vitamin and antioxidant supplements in the prevention of esophageal cancer. (J Cancer Prev 2013;18:135 $-143)$
\end{abstract}

Key Words: Vitamin supplements, Antioxidant supplements, Esophageal cancer, Randomized controlled trials, Meta-analysis

\section{INTRODUCTION}

According to GLOBOCAN 2008 published by the International Agency for Research on Cancer, esophageal cancer is the eighth most common cancer, with 3.8\% of all cancer cases, and the sixth leading cause of death from cancer, with $5.4 \%$ of all cancer deaths worldwide estimated in 2008. ${ }^{1}$ Along with genetic causes, lifestyle and environmental factors are considered to be important in the development of esophageal cancer. ${ }^{2}$ Among lifestyle factors, fruits and vegetables are rich in vitamins or antioxidants, which may have anticarcinogenic activities by various mechanisms removing free radicals and inhibiting the formation of N-nitroso compounds. ${ }^{2-4}$

Previous epidemiological studies have investigated the association between the risk of esophageal cancer and the intake of fruits and vegetables rich in vitamins and antioxidants, and those findings are mixed. In 2006, a

Received June 16, 2013, Revised June 19, 2013, Accepted June 19, 2013

Correspondence to: Seung-Kwon Myung

Department of Family Medicine, Hospital; Cancer Information \& Education Branch, National Cancer Control Institute; Center for Cancer Prevention and Detection, Hospital, National Cancer Center, Goyang 410-760, Korea

Tel: +82-31-920-0479; Fax: +82-31-920-2606, E-mail: msk@ncc.re.kr

Copyright (C) 2013 Korean Society of Cancer Prevention

(c) This is an Open Access article distributed under the terms of the Creative Commons Attribution Non-Commercial License (http://creativecommons. $\mathrm{org} /$ licenses/by-nc/3.0) which permits unrestricted non-commercial use, distribution, and reproduction in any medium, provided the original work is properly cited. 
meta-analysis of 10 epidemiological studies (1 cohort and 9 case-control studies) suggested that higher consumption of vitamin $\mathrm{C}$ and beta-carotene was significantly associated with a decreased risk of esophageal adenocarcinoma with odds ratios of 0.49 and 0.46 , respectively. ${ }^{5}$

In the meantime, several randomized controlled trials (RCTs $)^{6-15}$ have reported the association between vitamin or antioxidant supplements and the risk of esophageal cancer. However, no RCTs have suggested that there was any preventive efficacy of vitamin or antioxidant supplements on esophageal cancer. Further, there has been no quantitative meta-analysis of RCTs on this issue reported so far.

The purpose of this study was to examine the quantitative preventive efficacy of vitamin and antioxidant supplements on esophageal cancer by using a meta-analysis of RCTs by type of vitamin or antioxidant supplements, methodological quality, and high risk or non-high risk groups for esophageal cancer.

\section{MATERIALS AND METHODS}

\section{Data search}

We searched PubMed, EMBASE, and the Cochrane Library in May 2013, by using keywords related to vitamin and antioxidant supplements and esophageal cancer in RCTs. Also, the bibliographies of relevant articles were searched in order to locate additional studies. We used the following keywords for the literature search: "vitamin," "antioxidant," "beta-carotene," or "selenium; and "esophageal cancer.”

\section{Selection criteria}

We included RCTs that reported the preventive efficacy of vitamin or antioxidant supplements on esophageal cancer. The main outcome measure was cancer incidence.

\section{Selection of relevant trials}

Two evaluators (Dr. Myung SK, Dr. Yang HJ) independently screened all the studies searched from the three databases. We tried to contact the authors of the articles with insufficient data. From the trials included in the final analysis, we extracted the following data: study name, journal, country, duration of supplement treatment and follow-up period (years), population (project name), supplement interventions, relative risk (RR) with 95\% confidence intervals (CI), and number of cancer/number of participants in each intervention group.

\section{Main and subgroup analyses}

We examined the efficacy of vitamin and antioxidant supplements administered singly or in combination with other vitamin or antioxidant supplements on esophageal cancer, compared with placebo administration in all 10 trials. Also, we evaluated those efficacy by type of vitamin or antioxidant supplements, methodological quality, and high risk or non-high risk groups for esophageal cancer.

\section{Assessment of methodological quality}

We also evaluated the methodological quality of the trials by using the Jadad scale. ${ }^{16}$ This 5-point scale consists of randomization (2 points), double-blind (2 points), and follow-up (dropouts and withdrawals; 1 point) in the report of a RCT. A trial with the score of 2 or less was considered as having low-quality, and the one with the score of 3 to 5 was considered as having high-quality.

\section{Statistical analyses}

The pooled RR with 95\% CI was calculated on the basis of both the fixed- and random-effects models; the MantelHaenszel method was used in the fixed-effects model, and the DerSimonian and Laird method was used in the random-effects model. We estimated heterogeneity (between-studies variability) using the Higgins $\mathrm{I}^{2}$ statistic, which measures the percentage of total variation across studies due to heterogeneity rather than chance. ${ }^{17,18} \mathrm{I}^{2}$ was calculated as follows:

$$
\mathrm{I}^{2}=100 \% \times(\mathrm{Q}-\mathrm{df}) / \mathrm{Q}
$$

where Q is Cochran's heterogeneity statistic and df is the degrees of freedom corresponding to it. Cochran's Q statistic was calculated as follows:

$$
\mathrm{Q}=\Sigma(\theta \mathrm{i}-\theta p)^{2} W_{\mathrm{i}},
$$




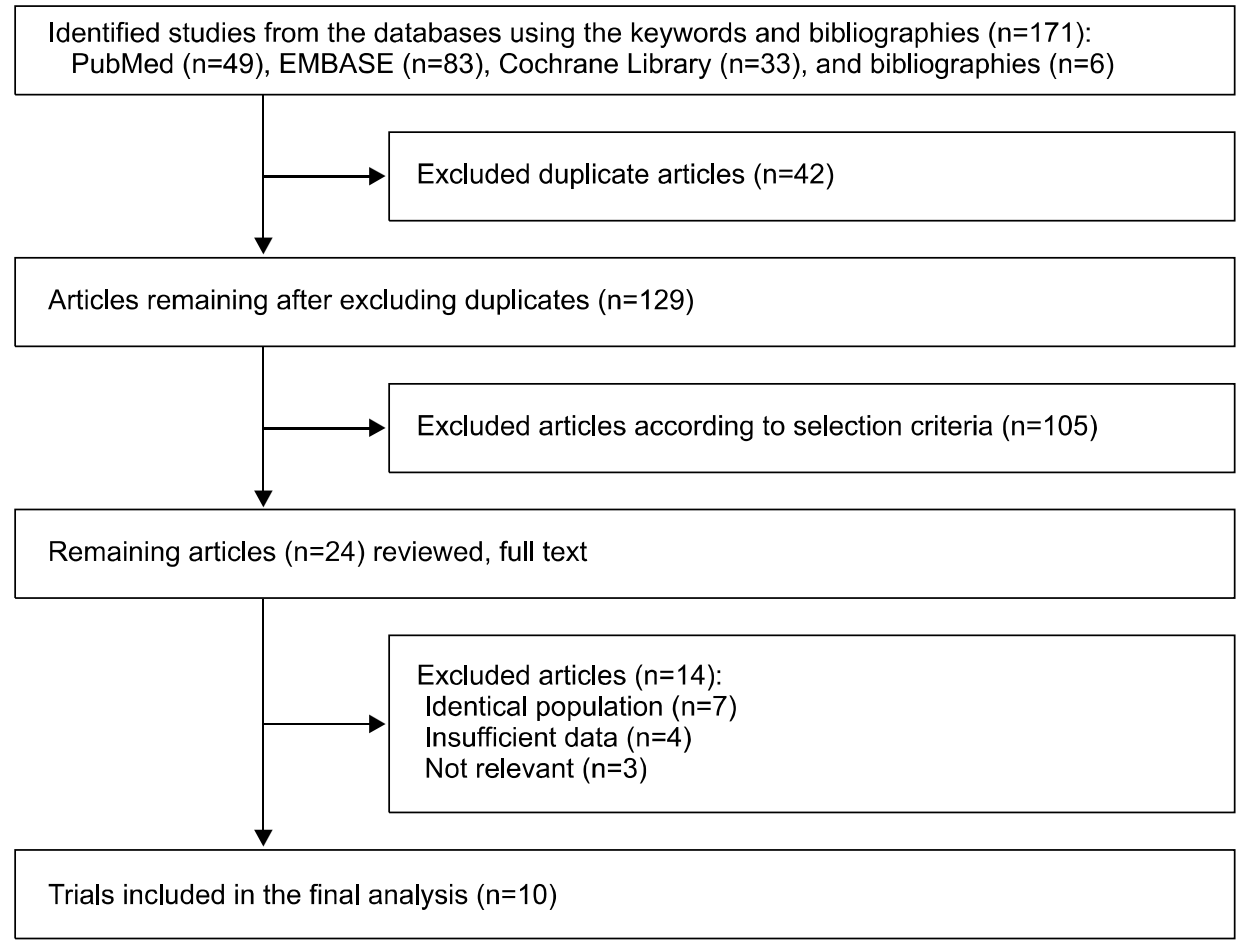

Fig. 1. Flow diagram for identification of relevant studies. where $\theta \mathrm{i}$ is the RR of each ith trial, $\theta \mathrm{p}$ is the pooled $\mathrm{RR}$ of all the trials, and wi is the inverse variance of each ith trial as a weight. Negative values of $\mathrm{I}^{2}$ are set at zero so that $\mathrm{I}^{2}$ ranges between 0\% (no observed heterogeneity) and 100\% (maximal heterogeneity). We considered an $\mathrm{I}^{2}$ value greater than $50 \%$ as indicating substantial heterogeneity. When there was no substantial heterogeneity, we reported the pooled estimate calculated based on the fixed-effects model. When there was substantial heterogeneity, we reported the pooled estimate calculated based on the random-effects model.

We estimated publication bias by using Begg's funnel plot and Egger's test. When the P-value was less than 0.05 by Egger's test, the presence of a publication bias was considered. We used the Stata SE version 10.0 software package (StataCorp, College Station, Texas, USA) for statistical analysis.

\section{RESULTS}

\section{Selection of trials}

A total of 171 articles were retrieved after searching three databases and relevant bibliographies (Fig. 1). After excluding duplicated articles and reviewing articles based on those title and abstracts, we reviewed 24 articles with those full texts and then included 10 trials in the final analysis. We excluded 14 articles because of identical populations ( $\mathrm{n}=7$ ), insufficient data $(\mathrm{n}=4)$, and studies not relevant to our subject $(n=3)$.

\section{General characteristics of trials}

A total of 126,828 subjects with the 70,959 vitamin and antioxidant supplement and 55,869 placebo groups from 10 RCTs. As shown in Table 1, the selected trials were published from 1985 through 2007, spanning 22 years. The countries in which the studies were performed were as follows: US ( $n=3)$, China ( $n=3)$, Finland ( $n=1)$, Canada ( $n=1$ ), UK $(n=1)$, and France $(n=1)$. The periods of treatment and follow-up ranges between 2 and 10.1 years. All trials used placebos as a control group. The types of vitamin and antioxidant supplements were vitamin A, vitamin B2, Vitamin C, vitamin E, beta-carotene, and selenium.

\section{Efficacy of vitamin or antioxidant supplements in all 10 trials}

In a fixed-effects model meta-analysis of all 22 trials, there was no efficacy of vitamin and antioxidant supplements in the prevention of esophageal cancer (RR, 1.04; 


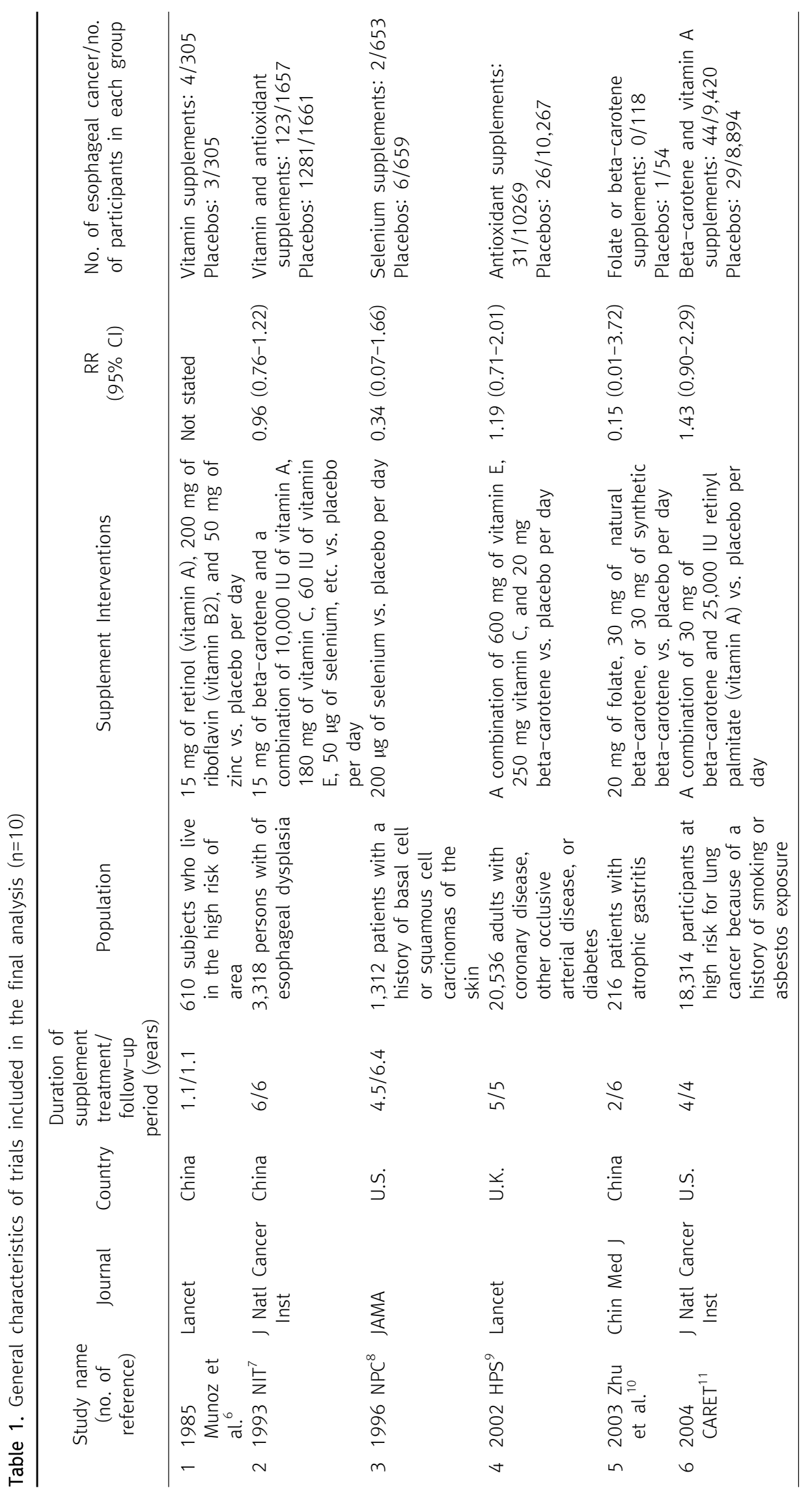




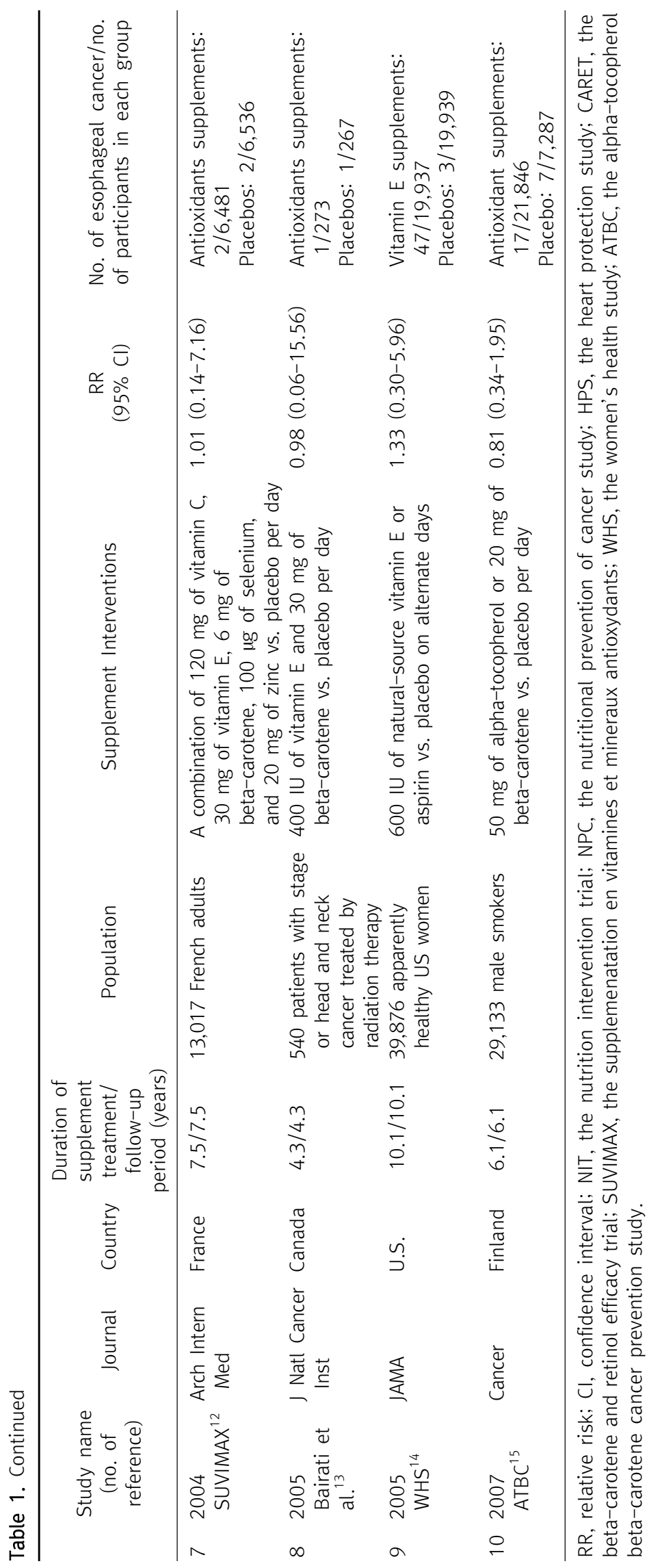




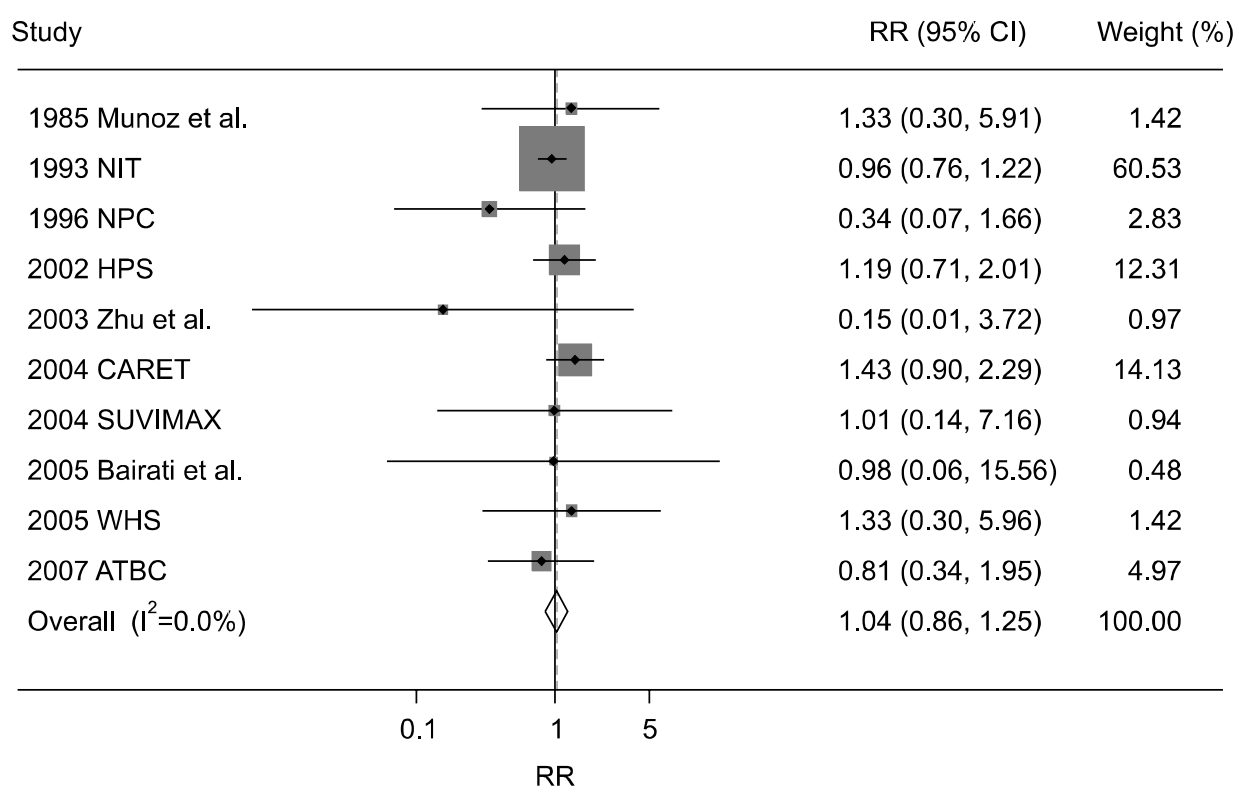

Fig. 2. Efficacy of vitamin and antioxidant supplements in prevention of esophageal cancer by a fixed-effect model meta-analysis of randomized controlled trials. $\mathrm{RR}$, relative risk; $\mathrm{Cl}$, confidence interval; NIT, the nutrition intervention trial; NPC, the nutritional prevention of cancer study; HPS, the heart protection study; CARET, the beta-carotene and retinol efficacy trial; SUVIMAX, the supplemenatation en vitamines et mineraux antioxydants; WHS, the women's health study; ATBC, the alpha-tocopherol beta-carotene cancer prevention study.

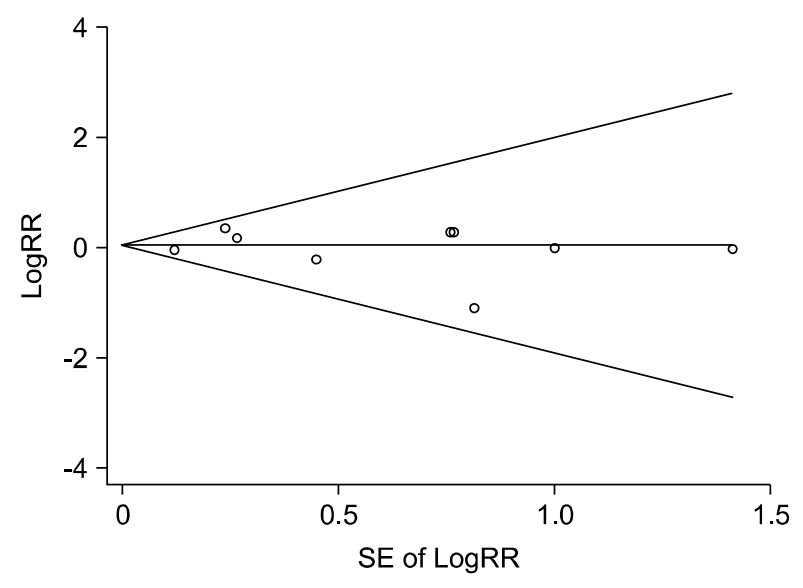

Fig. 3. Funnel plots and egger's test for identifying publication bias $(P=.913)$ in a meta-analysis of trials $(n=9)$. RR, relative risk; $\mathrm{SE}$, standard error.

95\% CI, 0.86-1.25; $\mathrm{I}^{2}=0.0 \%$ ) (Fig. 2). There was no evidence of publication bias in the selected studies (Egger's test, $\mathrm{P}$ for bias=0.913; The Begg's funnel plot was symmetrical) (Fig. 3).

\section{Methodological quality of trials}

Table 2 shows the methodological quality of trials based on the Jadad scale. Eight trials received 4 or higher points and were classified as having a high quality, whereas two trials received 3 points and were classified as having a low quality.

\section{Subgroup meta-analyses by type of supplements}

In the subgroup meta-analyses by type of supplements based on the fixed-effect model, none of the antioxidant supplements had any significant preventive efficacy in the prevention of esophageal cancer: vitamin A (RR, 1.06; 95\% CI, 0.86-1.30; $\mathrm{n}=3$ ), vitamin B2 (RR, 1.33; 95\% CI, 0.30-5.91; $n=1$ ), vitamin C (RR, 1.00; RR, 0.81-1.24: $n=3$ ), vitamin E (RR, 1.00; 95\% CI, 0.81-1.22; $\mathrm{n}=6$ ), folate (RR, 0.41; 95\% CI, 0.02-9.76), beta-carotene (RR, 1.05; 95\% CI, $0.87-1.27 ; \mathrm{n}=7$ ), and selenium (RR, 0.94; 95\% CI, 0.74-1.18; $n=3$ ) (Table 3).

\section{Subgroup meta-analyses by type of quality and risk group}

The subgroup meta-analyses by type of quality showed no preventive efficacy of vitamin and antioxidant supplements on esophageal cancer for both high quality (RR, 1.06; 95\% CI, 0.87-1.28; $n=8$ ) and low quality (RR, 0.70; 95\% CI, 0.31-1.61; n=2) trials. Similarly, no preventive efficacy was found in both high risk (RR, 1.04; 95\% CI, 0.85-1.28; n=4) and non-high risk (RR, 1.01; 95\% CI, 0.65-1.568; $n=6$ ) groups for esophageal cancer.

\section{DISCUSSION}

The current meta-analysis of RCTs found that there was 
Table 2. Methodological quality of trials based on the jadad scale $(n=10)$

\begin{tabular}{|c|c|c|c|c|c|c|c|}
\hline & $\begin{array}{c}\text { Source } \\
\text { (project name) }\end{array}$ & Randomization & $\begin{array}{l}\text { Description of } \\
\text { randomization } \\
\text { methods }\end{array}$ & Double-blind & $\begin{array}{l}\text { Using identical } \\
\text { placebo }\end{array}$ & $\begin{array}{c}\text { Follow-up } \\
\text { reporting }\end{array}$ & Total score \\
\hline 1 & 1985 Munoz et al. & 1 & 0 & 1 & 1 & 1 & 4 \\
\hline 2 & 1993 NIT & 1 & 0 & 1 & 1 & 1 & 4 \\
\hline 3 & 1996 NPC & 1 & 0 & 1 & 1 & 1 & 4 \\
\hline 4 & 2002 HPS & 1 & 1 & 1 & 1 & 1 & 5 \\
\hline 5 & 2003 Zhu et al. & 1 & 0 & 1 & 1 & 0 & 3 \\
\hline 6 & 2004 CARET & 1 & 0 & 1 & 1 & 1 & 4 \\
\hline 7 & 2004 SUVIMAX & 1 & 0 & 1 & 1 & 1 & 4 \\
\hline 8 & 2005 Bairati et al. & 1 & 1 & 1 & 1 & 1 & 5 \\
\hline 9 & 2005 WHS & 1 & 0 & 1 & 1 & 1 & 4 \\
\hline 10 & 2007 ATBC & 1 & 0 & 1 & 1 & 0 & 3 \\
\hline
\end{tabular}

NIT, the nutrition intervention trial; NPC, the nutritional prevention of cancer study; HPS, the heart protection study; CARET, the beta-carotene and retinol efficacy trial; SUVIMAX, the supplemenatation en vitamines et mineraux antioxydants; WHS, the women's health study; ATBC, the alpha-tocopherol beta-carotene cancer prevention study.

Table 3. Efficacy of vitamin and antioxidant supplements in prevention of esophageal cancer in subgroup meta-analyses

\begin{tabular}{|c|c|c|c|c|}
\hline Variable & No. of trials & Summary RR $(95 \% \mathrm{Cl})$ & Heterogeneity, $\left.\right|^{2}$ & Model used \\
\hline All & 10 & $1.04(0.86-1.25)$ & $0.0 \%$ & Fixed-effect \\
\hline \multicolumn{5}{|l|}{ Type of supplements } \\
\hline Vitamin A & 3 & $1.06(0.86-1.30)$ & $13.1 \%$ & Fixed-effect \\
\hline Vitamin B2 & 1 & $1.33(0.30-5.91)$ & NA & NA \\
\hline Vitamin C & 3 & $1.00(0.81-1.24)$ & $0.0 \%$ & Fixed-effect \\
\hline Vitamin E & 6 & $1.00(0.81-1.22)$ & $0.0 \%$ & Fixed-effect \\
\hline Folate & 1 & $0.41(0.02-9.76)$ & NA & NA \\
\hline Beta-carotene & 7 & $1.05(0.87-1.27)$ & $0.0 \%$ & Fixed-effect \\
\hline \multicolumn{5}{|l|}{ Methodological quality } \\
\hline High quality (score >3) & 8 & $1.06(0.87-1.28)$ & $0.0 \%$ & Fixed-effect \\
\hline Low quality (score $\leq 3$ ) & 2 & $0.70(0.31-1.61)$ & $0.0 \%$ & Fixed-effect \\
\hline \multicolumn{5}{|c|}{ Risk group for esophageal cancer } \\
\hline High risk group & 4 & $1.04(0.85-1.28)$ & $0.0 \%$ & Fixed-effect \\
\hline Non-high risk group & 6 & $1.01(0.65-1.56)$ & $0.0 \%$ & Fixed-effect \\
\hline
\end{tabular}

$\mathrm{RR}$, relative risk; $\mathrm{Cl}$, confidence interval; $\mathrm{NA}$, not applicable.

no efficacy of vitamin and antioxidant supplements in the prevention of esophageal cancer. Further, subgroup analyses by type of supplements, methodological quality, and risk group for esophageal cancer revealed no preventive efficacy of those supplements.

Our findings were inconsistent with those of previously published epidemiological studies and a meta-analysis of epidemiological studies, which had reported that people with the highest levels of antioxidant intake such as vitamin $\mathrm{C}$ or beta-carotene had an about 50\% lower risk compared to those with lower levels of intake. ${ }^{5}$

There are several possible explanations for the incon- sistent findings between observational epidemiological studies and RCTs. First, retrospective case-control studies are susceptible to recall and selection biases. ${ }^{18}$ Esophageal cancer patients might recall wrongly their consumption of fruit and vegetables rich in vitamin and antioxidants. Even though they had have adequate intakes of fruit and vegetables long before their diagnosis of esophageal cancer, they might think incorrectly that they had consumed less foods because they had dyspepsia and loss of appetite due to cancer right before that diagnosis. Also, selection bias might affect the results because cases or controls are not representative of the population. Second, there are dif- 
ferences in functions and components between natural vitamin or antioxidants and synthetic ones. For example, synthetic alpha-tocopherol (all-rac-alpha-tocopherol), which is composed of equal amounts of the 8 different stereoisomers of alpha-tocopherol, is different from its natural form (RRR-alpha-tocopherol). ${ }^{19}$ Also, the human body absorbs and excretes natural and synthetic vitamin $\mathrm{E}$ differently, and those biological activities are different. ${ }^{19,20}$ As for beta-carotene, experimental studies reported that beta-carotene might play a potential protective role against cancer initiation. ${ }^{21}$ However, it may act as a prooxidant in the presence of chronic oxidative stress such as smoking; this may induce the oxidation of beta-carotene and DNA oxidative damage and finally lead to lung cancer. $^{18,22}$

Third, eliminating reactive oxygen species by antioxidant supplementation might interfere with several essential defensive mechanisms like apoptosis and detoxification and unexpectedly increase mortality. ${ }^{23}$ Last, antioxidant supplements might have interdependency and show those efficacy only when given in combination. ${ }^{24}$

There are several limitations in our study. First, we were unable to include several recent $\mathrm{RCTs}^{25,26}$ because data for esophageal cancer were not reported. Second, the statistical power of the current meta-analysis is very low because the incidence of esophageal cancer is very low, compared with other types of common cancers. Further lager RCTs are needed to confirm our findings. Last, we were unable to apply our findings to healthy populations. Of 10 trials, only two trials involved general healthy populations, while the remaining trials involved a history of certain diseases or high risk populations for esophageal cancer.

In summary, unlike observational epidemiological studies, the current meta-analysis of RCTs found that there is no clinical evidence to support the efficacy of vitamin and antioxidant supplements in the prevention of esophageal cancer.

\section{ACKNOWLEDGEMENTS}

Seung-Kwon Myung is responsible for the initial plan, study design, data screening, data selection, data inter- pretation, statistical analysis, manuscript drafting, and for conducting the study.

Hyo Jin Yang is responsible for data screening and data selection. SK Myung is the guarantor for this paper and has full responsibility for this study.

\section{REFERENCES}

1. Ferlay J, Shin HR, Bray F, Forman D, Mathers C, Parkin DM. Estimates of worldwide burden of cancer in 2008: GLOBOCAN 2008. Int J Cancer 2010;127:2893-917.

2. Kubo A, Corley DA, Jensen CD, Kaur R. Dietary factors and the risks of oesophageal adenocarcinoma and Barrett's oesophagus. Nutr Res Rev 2010;23:230-46.

3. Steinmetz KA, Potter JD. Vegetables, fruit, and cancer. II. Mechanisms. Cancer Causes Control 1991;2:427-42.

4. Mirvish SS, Wallcave L, Eagen M, Shubik P. Ascorbate-nitrite reaction: possible means of blocking the formation of carcinogenic N-nitroso compounds. Science 1972;177:65-8.

5. Kubo A, Corley DA. Meta-analysis of antioxidant intake and the risk of esophageal and gastric cardia adenocarcinoma. Am J Gastroenterol 2007;102:2323-30.

6. Munoz N, Wahrendorf J, Bang LJ, Crespi M, Thurnham DI, Day NE, et al. No effect of riboflavine, retinol, and zinc on prevalence of precancerous lesions of oesophagus. Randomised double-blind intervention study in high-risk population of China. Lancet 1985;2:111-4.

7. Li JY, Taylor PR, Li B, Dawsey S, Wang GQ, Ershow AG, et al. Nutrition intervention trials in Linxian, China: multiple vitamin/mineral supplementation, cancer incidence, and disease-specific mortality among adults with esophageal dysplasia. J Natl Cancer Inst 1993;85:1492-8.

8. Clark LC, Combs GF Jr, Turnbull BW, Slate EH, Chalker DK, Chow J, et al. Effects of selenium supplementation for cancer prevention in patients with carcinoma of the skin. A randomized controlled trial. Nutritional Prevention of Cancer Study Group. JAMA 1996;276:1957-63.

9. Heart Protection Study Collaborative Group. MRC/BHF Heart Protection Study of antioxidant vitamin supplementation in 20,536 high-risk individuals: a randomised placebo-controlled trial. Lancet 2002;360:23-33.

10. Zhu S, Mason J, Shi Y, Hu Y, Li R, Wahg M, et al. The effect of folic acid on the development of stomach and other gastrointestinal cancers. Chin Med J (Engl) 2003;116: 15-9.

11. Goodman GE, Thornquist MD, Balmes J, Cullen MR, Meyskens FL Jr, Omenn GS, et al. The Beta-Carotene and Retinol Efficacy Trial: incidence of lung cancer and cardiovascular disease mortality during 6-year follow-up after stopping beta-carotene and retinol supplements. J Natl Cancer Inst 2004;96:1743-50.

12. Hercberg S, Galan P, Preziosi P, Bertrais S, Mennen L, Malvy D, et al. The SU.VI.MAX Study: a randomized, placebo-controlled trial of the health effects of antioxidant vitamins and minerals. Arch Intern Med 2004;164:2335-42. 
13. Bairati I, Meyer F, Gelinas M, Fortin A, Nabid A, Brochet F, et al. A randomized trial of antioxidant vitamins to prevent second primary cancers in head and neck cancer patients. J Natl Cancer Inst 2005;97:481-8.

14. Lee IM, Cook NR, Gaziano JM, Gordon D, Ridker PM, Manson JE, et al. Vitamin E in the primary prevention of cardiovascular disease and cancer: the Women's Health Study: a randomized controlled trial. JAMA 2005;294:56-65.

15. Wright ME, Virtamo J, Hartman AM, Pietinen P, Edwards BK, Taylor PR, et al. Effects of alpha-tocopherol and beta-carotene supplementation on upper aerodigestive tract cancers in a large, randomized controlled trial. Cancer 2007;109:891-8.

16. Jadad AR, Moore RA, Carroll D, Jenkinson C, Reynolds DJ, Gavaghan DJ, et al. Assessing the quality of reports of randomized clinical trials: is blinding necessary? Control Clin Trials 1996;17:1-12.

17. Higgins JP, Thompson SG. Quantifying heterogeneity in a meta-analysis. Stat Med 2002;21:1539-58.

18. Myung SK, Kim Y, Ju W, Choi HJ, Bae WK. Effects of antioxidant supplements on cancer prevention: meta-analysis of randomized controlled trials. Ann Oncol 2010;21:16679.

19. Kiyose C, Muramatsu R, Kameyama Y, Ueda T, Igarashi O. Biodiscrimination of alpha-tocopherol stereoisomers in humans after oral administration. Am J Clin Nutr 1997;65: 785-9.

20. Burton GW, Traber MG, Acuff RV, Walters DN, Kayden H,
Hughes L, et al. Human plasma and tissue alpha-tocopherol concentrations in response to supplementation with deuterated natural and synthetic vitamin E. Am J Clin Nutr 1998;67:669-84.

21. De Flora S, Bagnasco M, Vainio H. Modulation of genotoxic and related effects by carotenoids and vitamin A in experimental models: mechanistic issues. Mutagenesis 1999; 14:153-72.

22. Mayne ST, Handelman GJ, Beecher G. Beta-Carotene and lung cancer promotion in heavy smokers--a plausible relationship? J Natl Cancer Inst 1996;88:1513-5.

23. Bjelakovic G, Nikolova D, Gluud LL, Simonetti RG, Gluud C. Mortality in randomized trials of antioxidant supplements for primary and secondary prevention: systematic review and meta-analysis. JAMA 2007;297:842-57.

24. Hercberg S, Galan P, Preziosi P, Alfarez MJ, Vazquez C. The potential role of antioxidant vitamins in preventing cardiovascular diseases and cancers. Nutrition 1998;14: 513-20.

25. Lin J, Cook NR, Albert C, Zaharris E, Gaziano JM, Van Denburgh $\mathrm{M}$, et al. Vitamins $\mathrm{C}$ and $\mathrm{E}$ and beta carotene supplementation and cancer risk: a randomized controlled trial. J Natl Cancer Inst 2009;101:14-23.

26. Gaziano JM, Glynn RJ, Christen WG, Kurth T, Belanger C, MacFadyen J, et al. Vitamins $\mathrm{E}$ and $\mathrm{C}$ in the prevention of prostate and total cancer in men: the Physicians' Health Study II randomized controlled trial. JAMA 2009;301:52-62. 